\title{
Use of traditional medicine in severe edema amelioration of refractory congestive heart failure - case report
}

\author{
Zhu G* \\ Institute of Oncology of George Zhu, Beijing, China
}

\begin{abstract}
The main treatment to congestive heart failure is common source of western medicine. Here, a refractory heart failure was treated following traditional medicine with potential therapeutic benefits, suggesting its role of traditional medicine in heart disease especially in another myocardial infarction (for instance Suxiao Jiuxin pill, compound Danshen dripping pill DSP). In discussion, controlled delivery of injectable nanofibers with PDGFs and bFGF preserve myocardial function, which currently the care.
\end{abstract}

\section{Introduction}

Of all the ailments that may blow out life's little candle,heart disease [1] is the chief.. With the increased life span, the incidence of heart disease, as indicated by mortality statistics, has been steadily rising. The main treatment to congestive heart failure is common source of western medicine. At present, A rhematic heart disease complicated with severe heart failure is successfully treated after ingestion of traditional medicine as below.

\section{Case report}

A 64-year-old woman was admitted into hospital on Dec.18,2010 because of her serious heart disease. She was chief complaint of dyspnea (short breathing, and severe edema in both lower extremities and abdominal swelling. At physical examination on admission showed her facial swelling, accompanied with the symptoms of nausea and vomiting. The blood pressure was 120 systolic and 80 diastolic. Ear and ocular examinations were normal. There was venous distention in the neck, and no thyroid abnormality was found. She had barrel chest. She had palpitation and difficulty of breathing at rest, frequent episodes of proximal nocturnal dyspnea (orthopnea position, and attacks usually had a sleepless night. The heart rate was 140 times per minute, with irregular rhythm. A loud, harsh (grade IV) systolic murmur of moderate intensity was audible at the apex and transmitted along the left sternal border. The abdomen was greatly distended with a flat percussion note present in almost all areas. The flanks were bulging, and a fluid wave was elicited. No masses were palpable. The liver edge could be palpated at the costal margin and was slightly tender. Two plus pitting edema was present bilaterally from the knees downward. A diagnosis of rheumatic valvular heart disease (mitral valve insufficiency) complicated with congestive right heart failure (CRHF) was made. Past history further confirmed her heart disease through electrocardiograph (ECG, ultrasonic cardiogram (UCG) and CT scan during an episode of acute stroke on the beginning of Winter, 2008 in other hospital.

An approach to therapeutically protocol was taken by traditional medicine. Due to her disease progression. The traditional medicine consisted of Gastrodia elata, Codonopsis pilosula, Astragalus membranaceus, Red ginseng, Ligusticum wallichii, Angelica sinensis,
Ophiopogon japonicus, Schisandra chinensis, Fructus corni, emen ziziphi spinosae, Coix seed, Rhizoma Dioscoreae, Amomum villosum, Poria cocos wolf, Alisa orientale, Cordate houttuyniae, Orange peel, Licorice. After 15 days, edema was remarkedly disappeared. The heart rate declined to 120 times per minute. As an outpatient, he was continued to undergo the intermittent maintance therapy of traditional medicine. She was remained well 1.5 year later.

\section{Discussion}

In this study, a patient with congestive heart failure (CHR) was mandatory to better efficacy of traditional medicine at the period of no response to previous treatment. It seems likely that combination treatment of adjuvant traditional medicine was possibly valuable strategy in heart disease especially in preserve myocardial infarction function. This is testable.

PDGF has been identified as a major mitogen in serum for culture cells of mesenchymal origin. Platelet-derived growth factor (PDGF) from platelet is composed of two chains, A-chains and B-chains, which share $60 \%$ sequence identity, and which can dimerize to form the three combinations PDGF-AA, PDGF-BB, and PDGF-AB. There are two PDGF-receptor subunits (PDGFRA,PDGFRB) can associate as three dimer forms (alpha/alpha,alpha/beta,beta/beta) with variable binding specificity for the PDGF ligand dimers. Oncogenic receptor tyrosine kinase (RTKs) or also oncogenic receptor PDGFRA and PDGFRB mutants and/or fusions have been detected in many malignancies (for instances glioma, GIST and chronic eosinophilic leukemia) and their target therapy [2-6].

PDGF-BB, - AB, -CC induced cardiomyocyte akt phosphorylation and prevented apoptosis via PI3K/Akt signaling. A blinded and

Correspondence to: George Zhu, Institute of Oncology of George Zhu, Beijing, China, E-mail: sansan4240732 @163.com

Key words: heart disease, traditional medicine

Received: January 28, 2018; Accepted: February 18, 2018; Published: February 21,2018 
randomized study in 96 rats showed that injecting nanofibers with PDGF-BB decreased cardiomyocyte death, decreased infarct size after ischemia reperfusion, and preserved systolic function after myocardial infarction. This finding suggest that injectable nanofibers allow precise and sustained delivery of PDGFs to the myocadium with potential therapeutic benefits [7-10]. More recent, bFGF providing better strategy in this repair pathway in myocardial function. bFGF is mediated its signals via a FGF receptor (FGFR) [11]. Like other PDGFs, aberrant FGF expression can be alternatively spliced at deletion of $\mathrm{N}$ - or C-terminus into the categories of oncogenic receptor variants at chromosomal translocation [13], which are involved in epithelial mesenchymal transition (EMT) that produces invasive, metastatic features during tumor progression. This is our care of the safety factor of growth factors during clinical use.

\section{References}

1. Silber EN, Katz IN (1975) Heart Disease,697-751, MacMillan Publishing Co, New York.

2. Paugh BS, Zhu X, Qu C, Endersby R, Diaz AK, et al (2013) Novel oncogenic PDGFRA mutations in pediatric high-grade gliomas. Cancer Res 73: 6219-6229. [Crossref]

3. Jones AV, Cross NC (2004) Oncogenic derivatives of platelet-derived growth factor receptors. Cell Mol Life Sci 61: 2912-2923. [Crossref]

4. Matsumura I, Mizuki M, Kanakura Y (2008) Roles for deregulated receptor tyrosine kinase and their downstream signaling molecules in hematologic malignancies. Cancer Science 99: 479-88. [Crossref]
5. Lierman E, Lahortiga I, Miegroet HV, Mentes N, Marynen P, et al. (2007) The ability of Sorafenib to inhibit oncogenic PDGFRbeta and FLT3 mutants and overcome resistance to other small molecule inhibitors. Haematologica 92: 27-34. [Crossref]

6. Zhu G, Saboor-Yaraghi AA, Yarden Y, Santos J, Neil JC (2016) Downregulating oncogenic receptor:From bench to clinic. Hematology \& Medical Oncology 1: 30-40

7. Edelberg JM, Lee SH, Kaur M, Tang L, Feirt NM, et al. (2002) Platelet-derived growth factor- $\mathrm{AB}$ limits the extent of myocardial infarction in a rat model: feasibility of restoring impaired angiogenic capacity in the aging heart. Circulation 105: 608-613. [Crossref]

8. Hsieh PCH, Davis ME, Gannon J, MacGillivray C, Lee RT (2006) Controlled delivery of PDGF-BB for myocardial protection using injectable self-assembling peptide nanofibers. J Clin Invest 116: 237-248. [Crossref]

9. Li X, Tjwa M, Moons L, Fons P, Noel A, et al. (2005) Revascularization of ischemic tissues by PDGF-CC via effects on endothelial cells and their progenitors. J Clin Invest 115: 118-127. [Crossref]

10. Krausgrill B, Vantler M, Burst V, Raths M, Halbach M, et al. (2009) Influence of cell treatment with PDGF-BB and reperfusion on cardiac persistence of mononuclear and mesenchymal bone marrow cells after transplantation into acute myocardial infarction in rats. Cell Transplant 18: 847-853. [Crossref]

11. Takehara N, Tsutsumi Y, Tateishi K, Ogata T, Tanaka H, et al. (2008) Controlled delivery of basic fibroblast growth factor promotes human cadiosphere derived cell engraftment to enhance cardiac repair for chronic myocardial infarction. $J$ Am Coll Cardiol 52: 1858-1865. [Crossref]

12. Abdi J, Chen G, Cheng H (2013) Drug resistance in multiple myeloma: latest findings and new concepts on molecular mechanisms. Oncotarget 4: 2186-2207. [Crossref]

13. Holzmann K, Grunt T, Heinzle C, Sampl S, Steinhoff H, et al. (2012) Alternative splicing of fibroblast growth factor receptor IgIII loops in cancer. J Nucleic Acids 15: 950508.

Copyright: (C)2018 Zhu G. This is an open-access article distributed under the terms of the Creative Commons Attribution License, which permits unrestricted use, distribution, and reproduction in any medium, provided the original author and source are credited. 